I TRADIÇÃO \& INOVAÇÃO • ECONOMIA VERDE E INCLUSIVA
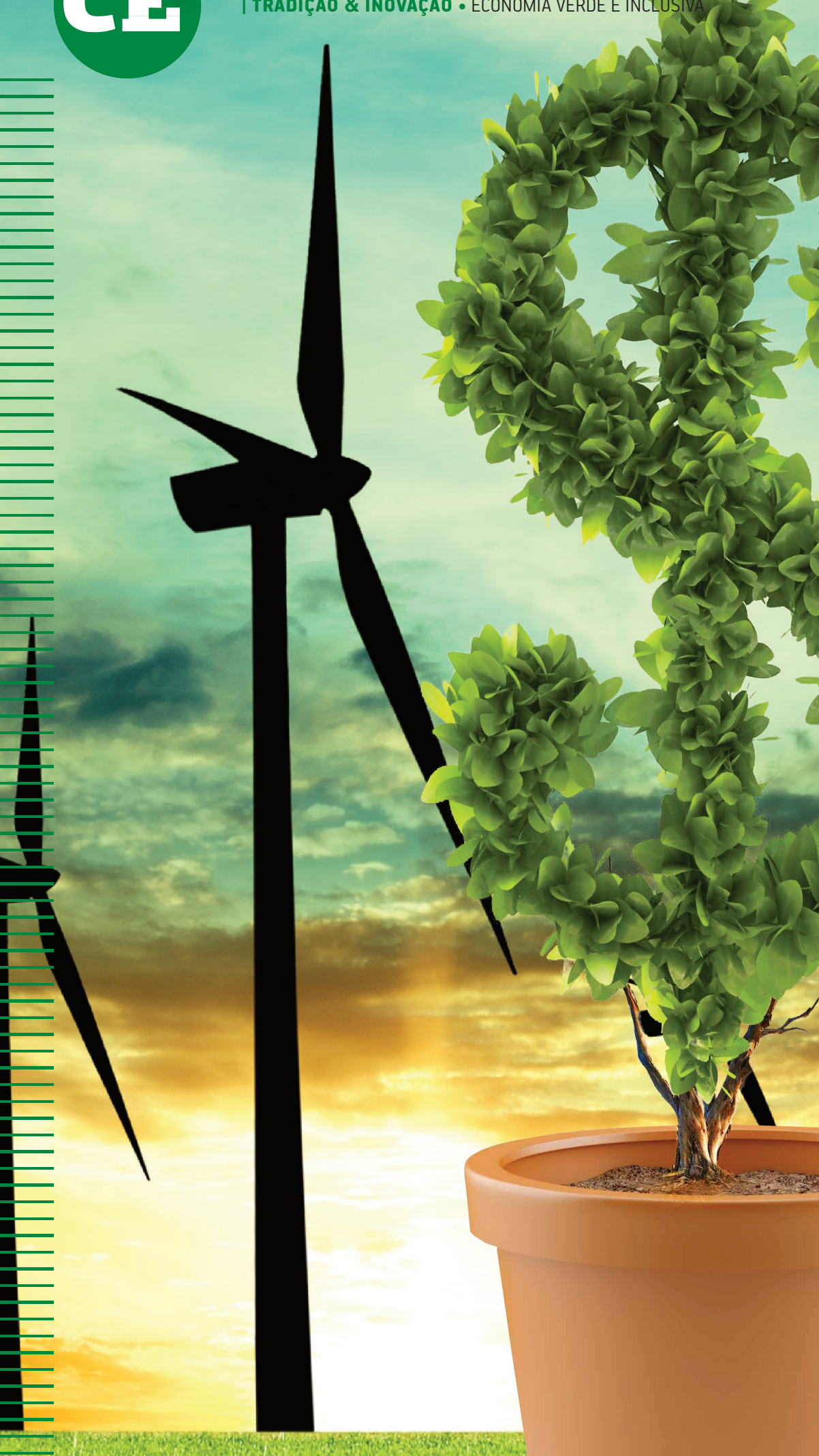

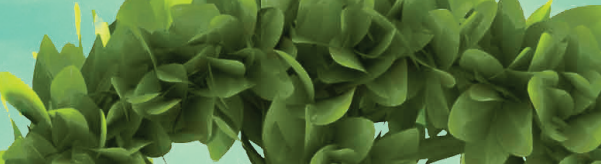

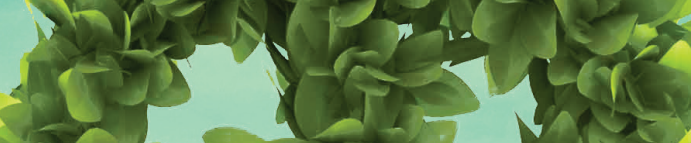



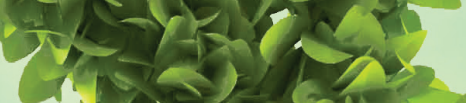

(1)

$4 y^{2}-(x-1)$

istar

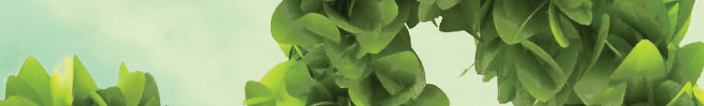

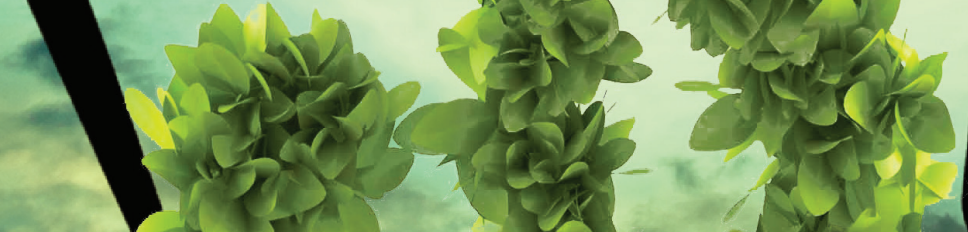

$(2)$

vedr ara

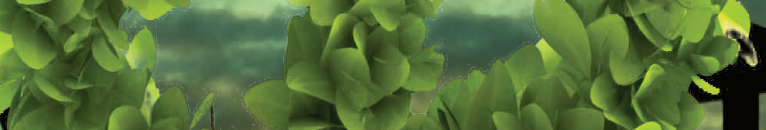




\section{ECONOMIA VERDE E INCLUSIVA}

\section{COMO EQUACIONAR DESENVOLVIMENTO, IGUALDADE SOCIAL E LIMITES AMBIENTAIS? PROPOSTAS RECENTES VÃO ALÉM DA QUESTÃO ÉTICA E APONTAM CAMINHOS QUE COMBINEM BEM-ESTAR E DINAMISMO ECONÔMICO}

\section{| POR ISABELA BALEEIRO CURADO + ARON BELINKY}

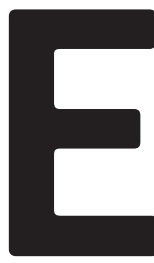

codesenvolvimento, desenvolvimento sustentável, economia verde... esses termos traduzem a preocupação com os desafios socioambientais, com a necessidade de incorporar a discussão sobre os limites à exploração dos recursos naturais tanto na formulação de políticas públicas quanto nas estratégias de iniciativas privadas - e com a ideia de construção de um sistema mais justo, inclusivo e igualitário.

Neste texto, trazemos à tona um tema que tem se revelado vital para o sucesso dos empreendimentos privados e públicos, incentivando-os a tomar atitudes que transformem consciência em ação e ameaça em oportunidade.

\section{HISTÓRICO}

O conceito de Ecodesenvolvimento foi introduzido na Conferência de Estocolmo (1972). Desenvolvido posteriormente pelo economista Ignacy Sachs (1974), compreende cinco dimensões da sustentabilidade: social, econômica, ecológica, espacial e cultural.

A partir da década de 1980, o termo Ecodesenvolvimento foi substituído por Desenvolvimento Sustentável, incorporando os seguintes princípios: integração da conservação da natureza com o desenvolvimento, satisfação das necessidades humanas fundamentais, busca de justiça e equidade social, aceitação da autodeterminação e diversidade social e, por fim, manutenção da integridade ecológica. Na preparação para a Eco 92, o Relatório Brundtland (1987) consolida o conceito, sintetizando-o na famosa frase: "Desenvolvimento que responde às necessidades do presente sem comprometer as possibilidades das gerações futuras satisfazerem suas próprias necessidades".
Mais recentemente, ganhou evidência o termo Economia Verde (EV), que vem se mesclando ao conceito de Desenvolvimento Sustentável. Ele se tornou mais presente a partir de iniciativas do Programa das Nações Unidas para o Meio Ambiente (PNUMA). A Iniciativa Economia Verde (IEV), lançada em 2008, define Economia Verde como aquela que busca tanto a melhoria do bem-estar humano e a igualdade social quanto a redução dos impactos e riscos ambientais.

Para o PNUMA, a EV tem três características predominantes: é pouco intensiva em carbono, eficiente no uso de recursos naturais e socialmente inclusiva. Na discussão preparatória para a Rio+20, o PNUMA lançou um relatório que propõe cinco fatores para a construção da EV: políticas sociais econômicas nacionais, direitos e capacitações locais, mercados verdes inclusivos, políticas e suporte a uma harmonização internacional e novos parâmetros para medir progresso.

\section{GESTÃO E ECONOMIA VERDE}

Se formos analisar os desafios da EV do ponto de vista de um gestor de negócios, é importante refletir:

- À medida que o negócio cresce, quais são seus impactos negativos para o meio ambiente e para a sociedade? Como isso se traduz em limites materiais ou aumento da resistência social ao seu crescimento?

- O que o negócio usa e não paga? Que efeito teria sobre seus resultados a cobrança dos recursos de uso comum e serviços ecossistêmicos que hoje não são contabilizados pela empresa, como geração de resíduos, uso da água, emissão de carbono e uso de espaço público? 


\section{ECONOMIA VERDE - SERÁ QUE É PARA VALER?}

Parte dos movimentos socioambientais e pesquisadores da área questionam se essa proposta representa transformações efetivas e desejáveis na gestão e prática de governos e empresas. No segmento ambiental, a crítica mais comum é que as mudanças são superficiais e de pouca relevância (greenwashing ou maquiagem verde), sendo muito mais um artifício para a melhoria da imagem corporativa. Na área social, a crítica está relacionada à mercantilização de bens comuns e esferas naturais, bem como a não modificação da estrutura do capitalismo no que se refere às práticas de gestão de custos, maximização dos lucros e apropriação dos resultados neste segmento.



Modelo Conceitual

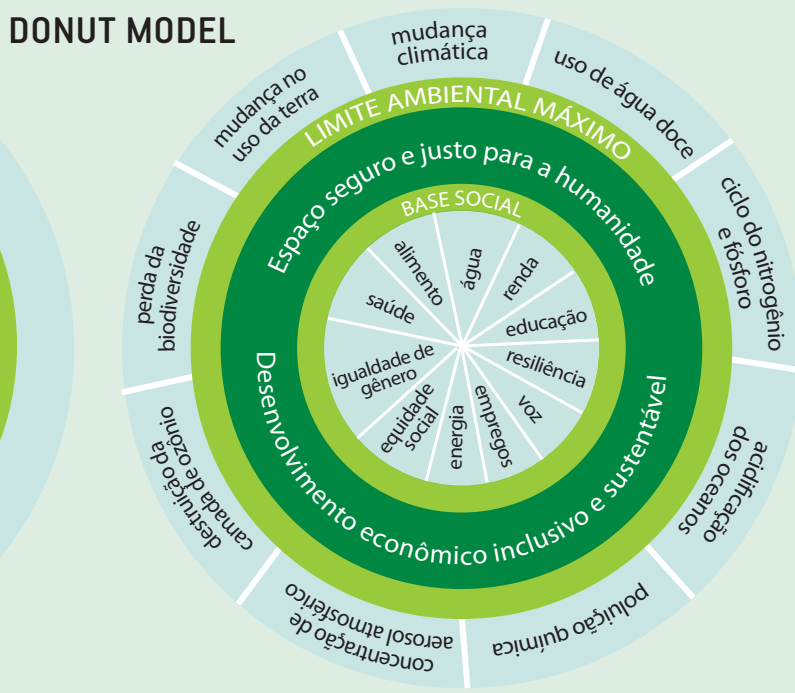

Dashboard/Indicadores

Fonte: Kate Raworth e Oxfam. Um espaço seguro e justo para a humanidade - podemos viver dentro de um donut? 2012.

A pensadora e economista Kate Raworth e a Oxfam (ONG global com foco na redução da pobreza e desigualdade) criaram o Donut Model - modelo que reflete os desafios do desenvolvimento global, inserindo os limites críticos da natureza no lado externo do donut e as necessidades humanas críticas no interno. Uma vez que os recursos são limitados e a população tem necessidades latentes, como podemos viver dentro do donut?

Desafios humanos — lado interno do donut. Exemplos da população mundial:

• 13\% está subnutrida

- 21\% vive com menos de US\$1,25 por dia

• 13\% não tem acesso à água potável
Limites ambientais - lado externo do donut. Segundo o artigo A safe operating space for humanity, publicado na revista Nature em 2009, ultrapassamos os limites ambientais máximos em três dimensões:

- Mudança climática

- Biodiversidade

- Ciclo de nitrogênio

\section{Esse modelo é inovador, pois:}

(a) Coloca no mesmo plano, de forma totalmente integrada, as dimensões social, ambiental e econômica.

(b) Cria um dashboard (painel de controle) com variáveis mensuráveis para o acompanhamento e a gestão do sistema. 
Diferentemente dos modelos econômicos atualmente em uso, o donut economics incorpora, por um lado, a noção de limites ambientais à expansão econômica e propõe, por outro, exigências sociais mínimas, medidas pelo nível do atendimento às necessidades essenciais da população. Nessa proposta, metas e modelos econométricos iriam além dos indicadores tradicionais (PIB, coeficiente de Gini, inflação, taxa de juros etc.) e passariam a incluir variáveis representativas dos limites ambientais e exigências sociais mínimas. O objetivo final é atender às demandas da população sem extrapolar esses limites.

A gestão do sistema, sintetizada no dashboard, desdobra-se em fatores que refletem a complexidade do mundo atual, interdependente e globalizado. Coloca objetivamente questões cuja solução passa, necessariamente, pela combinação de esforços científicos, tecnológicos, comportamentais e políticos.

- Quais são as capacidades e limites na incorporação de novos consumidores? Existe uma parcela significativa da sociedade que não tem acesso a bens básicos, enquanto o padrão de consumo da alta classe média não poderia ser reproduzido para a sociedade como um todo: se todos consumissem como a média da população norte-americana, seriam necessários quatro planetas Terra. Uma vez que a ecoeficiência tem limites, é necessário pensar, por um lado, em modelos de consumo mais inclusivos e, por outro, menos perdulários e impactantes.

Responder essas três questões é um importante caminho para a análise das possibilidades de sucesso em longo prazo de empreendimentos novos ou existentes. Em resposta a essas e outras perguntas, estudos e compromissos no campo da produção e consumo sustentáveis têm sido desenvolvidos, tanto no âmbito público como no privado, apontando que a solução dos problemas requer mudanças profundas.

As questões que se colocam, ao pensarmos em economia verde e inclusiva, são: que tipo de desenvolvimento queremos? Que tipo de sociedade buscamos? Quais devem ser as prioridades da humanidade como um todo? Manter a situação atual já se mostrou inviável e a movimentação rumo a um novo modelo ainda está longe do necessário.

\section{UM NOVO HORIZONTE}

Porém, já é possível verificar, em algumas experiências, a concretização de tendências de mudança para um mundo capaz de abrigar dignamente as presentes e futuras gerações.

Por exemplo, a Alemanha tem como diretriz desligar as suas 17 centrais nucleares até 2020, substituindo-as gradativamente por fontes de energia limpas e renováveis (de 35\% em 2020 para $80 \%$ em 2050). Para isso, tem adotado múltiplas soluções, incluindo a energia eólica, que já responde por 7,7\% da eletricidade do país, com 32 gigawatts (GW) de capacidade instalada (o triplo da hidrelétrica de Belo Monte, em construção no rio Xingu). Outra solução alemã é o modelo de geração descentralizada de energia, que já envolve 4 milhões de produtores individuais domésticos, cujos painéis solares fornecem eletricidade excedente para a rede. No Brasil, essa solução também é viável, e as primeiras instalações já começam a gerar energia no sertão nordestino.

O outro exemplo - vigente em cidades da Europa e que, em 2014, começa a operar em Curitiba - é a adoção de modelos de transportes urbanos mistos, com os modais públicos de massa sendo complamentados por miniautomóveis elétricos de uso compartilhado, como as bicicletas já muito utilizadas.

Esses poucos, mas eloquentes exemplos, ilustram bem o tamanho das mudanças já em curso ou em rápida maturação e alertam para a importância da atenção redobrada do empresariado frente ao futuro breve.

Em poucas décadas, a questão do desenvolvimento sustentável evoluiu rapidamente, convertendo-se de conceito idealizado em tendência contemporânea, já tangível em várias áreas da economia e cada vez mais presente no imaginário do consumidor. Soluções paliativas ou incrementos tecnológicos não serão, isoladamente, capazes de resolver a equação socioeconômica e ambiental da qual depende nosso futuro. Enquanto organizações acadêmicas e lideranças políticas e sociais desenvolvem modelos e novos arranjos institucionais para lidar com esses desafios, empresas de visão têm investido em soluções concretas para necessidades emergentes, antecipando-se para ocupar os mais promissores nichos do novo cenário.

Para os gestores e líderes empresariais, conhecer as tendências mais recentes e responder a certas perguntas críticas é um caminho fundamental para identificar suas forças e fraquezas, possibilitando, assim, minimizar riscos e agir com proatividade, visando a uma sociedade mais justa e sustentável.



ISABELA BALEEIRO CURADO > Professora da FGV-EAESP > isabela.curado@fgv.br ARON BELINKY > Professor da FGV-EAESP > aron.belinky@fgv.br 